\title{
Effect of Temperature on Torsional Properties of Ni-Ti and Copper Ni-Ti Orthodontic Wires
}

\author{
M.P. Filleul****, R. Portier* and L. Jordan**** \\ * Laboratoire de Métallurgie Structurale, ENSCP, 11 rue Pierre et Marie Curie, 75231 Paris cedex 05, \\ France \\ ** Faculté de Chirurgie Dentaire, Université René Descartes Paris V, Paris, France \\ *** Faculté de Chirurgie Dentaire, Université Denis Diderot Paris VII, Paris, France
}

\begin{abstract}
The behaviour of $\mathrm{Ni}-\mathrm{Ti}$ and Copper $\mathrm{Ni}$-Ti orthodontic wires was tested under induced torsion in controlled conditions of moment and temperature. The results clearly demonstrate a great difference in the behaviour of thesc wires. The loading and unloading curves and plateau regions were found to be closely related to temperature. Experiments carried out in conditions of identical torsion revealed significant variations in stiffness due to changes in mouth temperature. Diversity of reaction to stress is linked to the crystalline structurc of the alloys.
\end{abstract}

\section{INTRODUCTION}

Knowledge of the magnitude of torque applied to the tooth for a given amount of torsion on orthodontic wires is of the utmost importance to the clinician. Orthodontists have long varied the forces by changing the thickness of the same alloy wires in order to move the teeth. Today new alloys are available which could be used to modulate forces of identical cross-section wires $[1]$. Researchers have studied orthodontic wires under bending [2-3] but few torsion experiments have been reported. The behaviour of wires under torsion is very different from their behaviour under flexion and this due to the fact that distance between orthodontic brackets induces different stiffness of the arch-wire depending on whether flexion or torsion is applied. Thus, the inter-bracket distance varies by third power law in flexion whereas in torsion the variation is linear.

The purpose of this study was to test $\mathrm{Ni}-\mathrm{Ti}$ and Copper Ni-Ti orthodontic wires in torsion. Evaluation and comparison of their pseudoelastic properties (superelastic and memory effect) are dealt with in this paper. Superelasticity and memory effect are linked to structural changes at certain temperatures [4]. The structural state at high temperature is that of the austenite, and at low temperature it is that of the martensite or the Rphase (depending on the alloy used)[5-6]. The results will then be discussed using Differential Scanning Calorimetry (DSC). This method allows identification of the crystallographic phases of alloys at various temperatures [7].

\section{MATERIALS AND METHODS}

An original testing bench (figure 1) was used to test orthodontic wires under induced torsion in controlled clinical conditions of moment and temperature [8]. The system is immersed in a thermostatically controlled waterbath. The tests on torsion are conducted at the level of the right central incisor. In clinical conditions, moments of more than $1400 \mathrm{~g} . \mathrm{mm}$ are not generally applied to central incisors, but the test was performed at higher values than normal in order to observe the wire properties. To study superelasticity, each wire was loaded at $22^{\circ} \mathrm{C}$ (room temperature) with moments varying from $0 \mathrm{~g} . \mathrm{mm}$ to $1680 \mathrm{~g} . \mathrm{mm}$ and was unloaded at $37^{\circ} \mathrm{C}$ (buccal temperature). To study memory effect, the arch wires were cooled at $0^{\circ} \mathrm{C}$ and were loaded at $10^{\circ} \mathrm{C}$ in order to measure the degree increase when moments varied from $0 \mathrm{~g} . \mathrm{mm}$ to 1260 g.mm and when they were unloaded at $37^{\circ} \mathrm{C}$. The values of torsion angles (degrees) are plotted on six graphs (figures 2 to 7 ).

Four commercial orthodontic archwires were studied (Table 1). All the wires were available as preformed archwires. The exact composition and thermo-mechanical treatments of these wires are unknown. The archwires were submitted to torsion tests in order to evaluate the restored torque. Restored moments of different $\mathrm{Ni}$ - Ti alloys are compared to those of stainless steel in the same conditions. The section of brackets bonded to the dental arch simulator is $0.018 \times 0.025$ inches $\left(0.46 \times 0.64 \mathrm{~mm}^{2}\right)$ and the section of the tested wires is $0.017 \times 0.025$ inches $\left(0.435 \times 0.64 \mathrm{~mm}^{2}\right)$ or $0.018 \times 0.025$ inches $\left(0.46 \times 0.64 \mathrm{~mm}^{2}\right)$. 

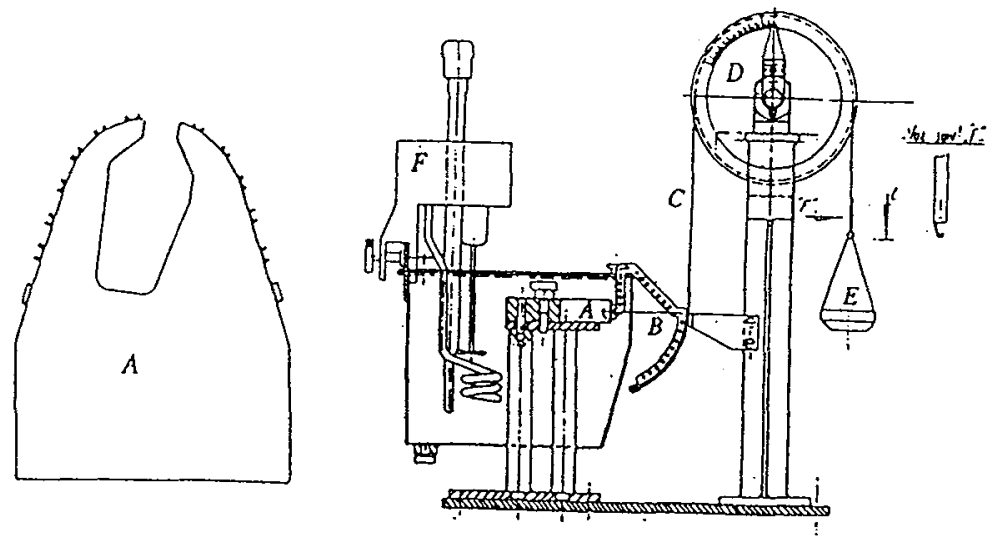

Figure $1:$ The testing bench-A dental arch simulator $; B$ lever $; C$ strip of iron;

$D$ graduated pulley, Eweight; $F$ thermostatic bobbing heater.

\begin{tabular}{|c|c|c|}
\hline Material & Nominaldiameter & Manufacturer/supplier \\
\hline $\begin{array}{l}\text { US Ni-Ti@ } \\
\text { Broad arch. Upper/small }\end{array}$ & $\begin{array}{l}0.017 \times 0.025 \text { inches } \\
\left(0.435 \times 0.64 \mathrm{~mm}^{2}\right)\end{array}$ & $\begin{array}{l}\text { Ormco Corporation, } \\
\text { Glendora, CA USA }\end{array}$ \\
\hline $\begin{array}{l}\text { Neo Sentalloy } \mathrm{F} 100 \AA \\
\text { Standard }\end{array}$ & $\begin{array}{c}0.018 \times 0.025 \text { inches } \\
\left(0.46 \times 0.64 \mathrm{~mm}^{2}\right)\end{array}$ & $\begin{array}{l}\text { GACInternational } \\
\text { Inc. Japan }\end{array}$ \\
\hline $\begin{array}{l}\text { Copper Ni-Ti } 35 \otimes \\
\text { Broad arch.Upper/small }\end{array}$ & $\begin{array}{l}0.017 \times 0.025 \text { inches } \\
\left(0.435 \times 0.64 \mathrm{~mm}^{2}\right)\end{array}$ & $\begin{array}{l}\text { Ormco Corporation, } \\
\text { Glendora, CA USA }\end{array}$ \\
\hline $\begin{array}{l}\text { Copper Ni-Ti } 40 \AA \\
\text { Broad arch.Upper/small }\end{array}$ & $\begin{array}{l}0.017 \times 0.025 \text { inches } \\
\left(0.435 \times 0.64 \mathrm{~mm}^{2}\right)\end{array}$ & $\begin{array}{l}\text { Ormco Corporation, } \\
\text { Glendora, CA USA }\end{array}$ \\
\hline $\begin{array}{l}\text { Arch Stainless Steel } \\
(18.8)\end{array}$ & $\begin{array}{c}0.018 \times 0.025 \text { inches } \\
\left(0.46 \times 0.64 \mathrm{~mm}^{2}\right)\end{array}$ & $\begin{array}{l}\text { Ormco Corporation, } \\
\text { Glendora, CA USA }\end{array}$ \\
\hline
\end{tabular}

Table I: Details on the various archwires used.

Differential Scanning Calorimetry measurements (DSC) were used to determine the transformation temperatures of these Ni-Ti wires. DSC measurements were performed by a Mettler 30/TA 4000 machine. The cooling/heating rate is $5^{\circ} \mathrm{C} / \mathrm{min}$. The DSC samples of the wire were cut at the level of the central incisor. The different transformation temperatures are presented on Table 2. The transformations were exothermic on cooling, and endothermic on heating.

\begin{tabular}{|c|c|c|c|c|c|c|}
\hline \multirow[b]{2}{*}{ Material } & \multicolumn{4}{|c|}{$\begin{array}{l}\text { Transformation } \\
\text { on cooling }\left({ }^{\circ} \mathrm{C}\right)\end{array}$} & \multirow{2}{*}{\multicolumn{2}{|c|}{$\begin{array}{c}\text { Transformation on } \\
\text { heating }\left({ }^{\circ} \mathrm{C}\right) \\
\mathrm{R} \rightarrow \mathrm{A}\end{array}$}} \\
\hline & \multicolumn{2}{|c|}{$A \rightarrow R$} & \multicolumn{2}{|c|}{$\mathrm{R} \rightarrow \mathrm{M}$} & & \\
\hline $\begin{array}{l}\text { US Ni-Ti® } \\
\text { Neo Sentalloy F } 100 \otimes\end{array}$ & $\begin{array}{l}\text { Start } \\
24.5 \\
21.7 \\
\end{array}$ & $\begin{array}{c}\text { Finish } \\
14 \\
14.5\end{array}$ & $\begin{array}{r}\text { Start } \\
-35,5 \\
-21.7 \\
\end{array}$ & $\begin{array}{c}\text { Finish } \\
-98 \\
-47.4\end{array}$ & $\begin{array}{l}\text { Start } \\
19.8 \\
20.5\end{array}$ & $\begin{array}{c}\text { Finish } \\
29 \\
27.2\end{array}$ \\
\hline & & \multicolumn{2}{|c|}{$\mathrm{A} \rightarrow \mathrm{M}$} & & \multicolumn{2}{|c|}{$M \rightarrow A$} \\
\hline $\begin{array}{l}\text { Copper Ni-Ti } 35 \otimes \\
\text { Copper Ni-Ti } 40 \otimes\end{array}$ & & $\begin{array}{l}\text { Start } \\
17.5 \\
20.2\end{array}$ & $\begin{array}{c}\text { Finish } \\
-8.5 \\
3\end{array}$ & & $\begin{array}{l}\text { Start } \\
14.2 \\
24.5\end{array}$ & $\begin{array}{c}\text { Finish } \\
36.3 \\
40\end{array}$ \\
\hline
\end{tabular}

Table 2: Transformation temperatures determined by DSC during cooling or heating.

The DSC experiments show that it is the $\mathrm{A} \leftrightarrow \mathrm{R}$ transformation which occurs in the case of US Ni-Ti® and Neo Sentalloy F100B, and the A $\leftrightarrow$ M transformation which occurs in the case of Copper Ni-Ti $35 \otimes$ and Copper $\mathrm{Ni}$-Ti $40 \otimes$. 


\section{RESULTS}

In order to study superelasticity, each wire is loaded at $22^{\circ} \mathrm{C}$ and unloaded at $37^{\circ} \mathrm{C}$. To observe memory effect, the wires are loaded at $10^{\circ} \mathrm{C}$ and unloaded at $37^{\circ} \mathrm{C}$. In the graphs, the thin lines correspond to the loading wire and the thick lines to the unloading wire.

There is a certain gap between the section of these wires and the brackets. Torsion play is evaluated at $4.5^{\circ}$ maximum [9]. This explains the behaviour of wires in the first $4-5^{\circ}$ degrees of torsion.

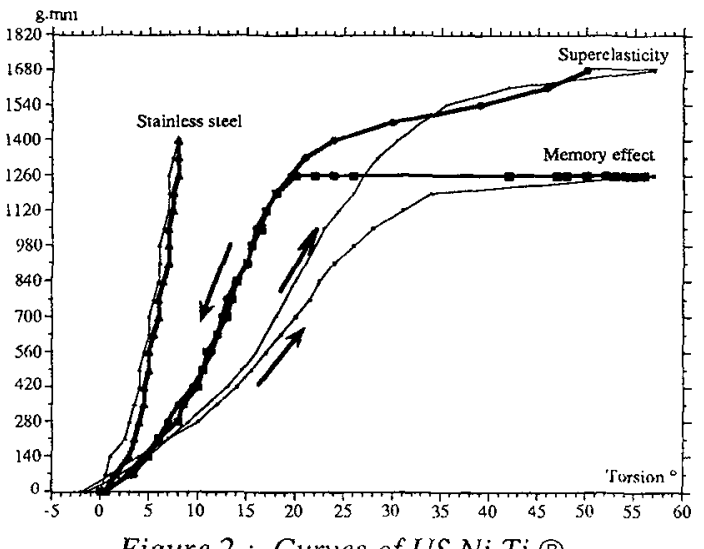

Figure 2: Curves of US Ni-Ti $($ ).

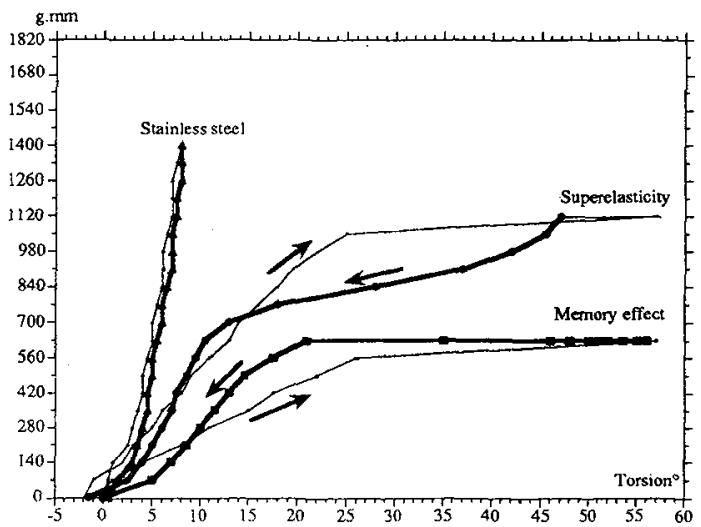

Figure 3 : Curves of Neo Sentalloy $F 100 \AA$.

US Ni-Ti® (fig. 2): With superelastic and memory effects, the unloading slopes are similar, only the unloading plateaux are different. The loading slopes are more gradual than the unloading slopes in the case of two properties.

Neo Sentalloy $\AA$ (fig. 3) and Copper Ni-Ti 35® (fig. 4) show the same behaviour in memory effect : the loading slope is more gradual than the unloading slope. This is not the case with superelasticity : the loading and unloading slopes are similar.

Copper Ni-Ti $40 \AA$ (fig. 5) curves are similar to Copper Ni-Ti 35® curves in memory effect, but the plateau level is inferior. In superelasticity, the loading slope is more gradual than the unloading slope. After unloading, this wire shows a certain deformation which is greater in superelasticity than in memory effect. Figures 2 to 5 show that the temperature does not modify the elastic behaviour of stainless steel.

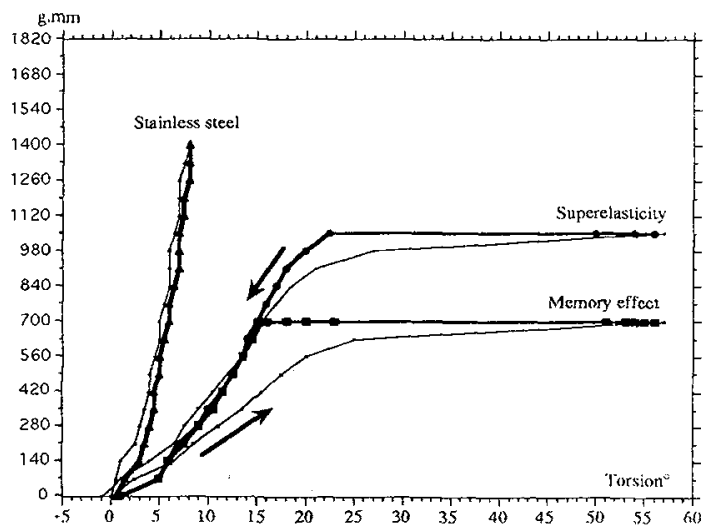

Figure 4 : Curves of Copper Ni-Ti $35 \AA$.

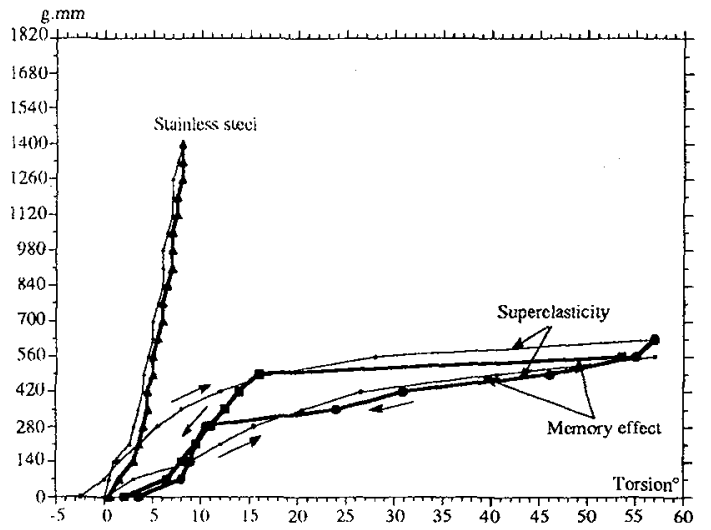

Figure 5: Curves of Copper Ni-Ti $40 \AA$.

All the diagrams show characteristic curves of superelasticity and memory effect. All the curves in torsion present, on loading, a slope followed by what is more or less a plateat and, on unloading, a plateau 
followed by a slope. All the wires in memory effect show an unloading plateau which is lower than that recorded for superelasticity.

Apart from Copper $\mathrm{Ni}-\mathrm{Ti} 40 \circledast$, all the wires, after unloading, return to their original shape. This behaviour during unloading is very important : it corresponds to tooth movement.

Superposition (fig. 6 and 7) of the curves of differen wires permits a comparison between superelasticity and memory effect.

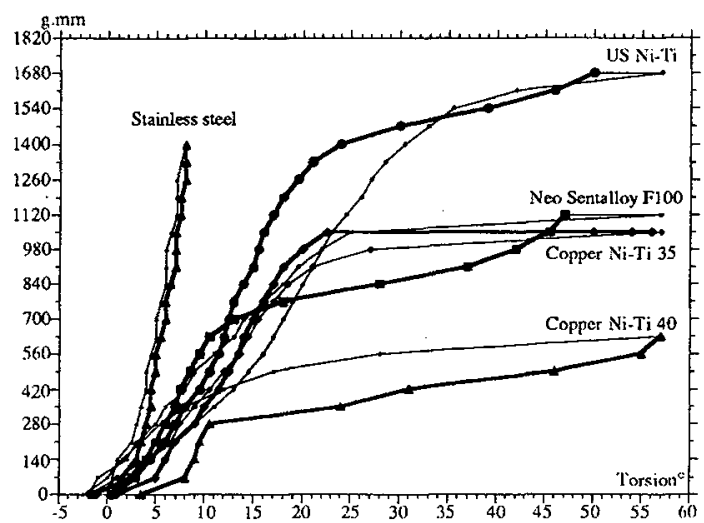

Figure 6 : Superelasticity.

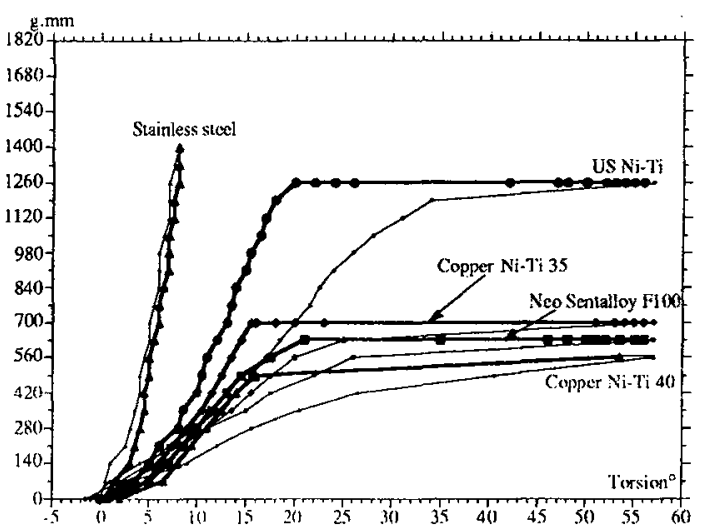

Figure 7 : Memory effect.

Analysis of these different wires allows them to be classified in order of decreasing restored moment at the plateau values level (table 3 ). This order is not the same for superelasticity and memory effect.

Memory effect : MUS Ni-Ti $>M_{\text {CopperNi-Ti } 35}>M_{N S ~ F 1(0)}>M_{\text {CopperNi-Ti 40 }}$;

Superelasticity: MUS Ni-Ti $>M_{N S ~ F 100}>M_{\text {CopperNi-Ti } 35}>M_{\text {CopperNi-Ti } 40 .}$

\begin{tabular}{|l||c|c||c|c|}
\hline \multicolumn{1}{|c||}{ Wire } & \multicolumn{2}{c|}{$\begin{array}{c}\text { Memory effect } \\
\text { Torsion } \\
\text { Restored M } \\
(\text { g.mm) }\end{array}$} & $\begin{array}{c}\text { Superelasticity } \\
\text { Torsion } \\
(\text { O) }\end{array}$ & $\begin{array}{c}\text { Restored M } \\
(\text { g.mm) }\end{array}$ \\
\hline US Ni-Ti $\odot$ & $57 \rightarrow 20$ & 1260 & $57 \rightarrow 21$ & $1680 \rightarrow 1330$ \\
Copper Ni-Ti 35® & $57 \rightarrow 15$ & 700 & $57 \rightarrow 20$ & $1050 \rightarrow 980$ \\
Neo Sentalloy F100@ & $57 \rightarrow 20$ & 630 & $57 \rightarrow 12$ & $1120 \rightarrow 700$ \\
Copper Ni-Ti 40® & $57 \rightarrow 15$ & 560 & $57 \rightarrow 11$ & $630 \rightarrow 280$ \\
\hline
\end{tabular}

Table $3:$ Restored moments in memory effect and superelasticity at the plateata levels.

These torsion tests show the difference of behaviour of $\mathrm{Ni}$ - Ti and Copper Ni-Ti wires under similar stress when environmental temperatures change. Diversity of reaction to stress is linked to the crystalline structure of the alloys, and this is investigated by DSC (Table 2).

\section{DISCUSSION}

The DSC graphs during cooling give the structural state of the wires before loading at a certain temperature, and thus, during heating, enable us to estimate the behaviour of the wire during unloading (when teeth are moving). Stainless steel does not show any transformation at buccal temperature. Magnitude of stress applied to the teeth is not linked to buccal temperature. Loading and unloading slopes are the same.

US Ni-Ti® : The transformation from the austenitic state to the R-phase takes place at $24.5^{\circ} \mathrm{C}$. This explains why the slope of the curve at $22^{\circ} \mathrm{C}$ is lower than the slope of the curve at $37^{\circ} \mathrm{C}$. At $22^{\circ} \mathrm{C}$, on loading, the material is certainly biphased (austenite and R-phase) and at $37^{\circ} \mathrm{C}$, it is in the austenitic phase. In fact, the R-phase elastic modulus is much lower than the austenitic phase. After cooling at $0^{\circ} \mathrm{C}$, the material is entirely in R-phase and the loading slope at $10^{\circ} \mathrm{C}$ is lower than that at $22^{\circ} \mathrm{C}$. For the same amount of torsion of an edgewise wire, the developed moments at $10^{\circ} \mathrm{C}$ will be weaker than those developed at $22^{\circ} \mathrm{C}$. 
After unloading, the wire returns to its original shape $\left(0^{\circ}\right.$ torsion) because the reverse transformation $\rightarrow \mathrm{A}$ ) is finished at $29^{\circ} \mathrm{C}$, a temperature which is lower than buccal temperature.

In the case of Neo Sentalloy F100®, at $22^{\circ} \mathrm{C}$ when stress is applied, the material is austenitic $\left(\mathrm{T}_{\mathrm{R}}=\right.$ $21.7^{\circ} \mathrm{C}$ ), and the mechanical energy applied during loading is sufficient to allow the R-phase to appear. The orthodontist can advantageously use superelasticity. After cooling at $0^{\circ} \mathrm{C}$, the material is entirely in R-phase and the orthodontist can use memory effect. After unloading, as in the case of US Ni-Ti $\odot$, the wire returns to its original shape $\left(0^{\circ}\right.$ torsion) because the reverse transformation $(R \rightarrow A)$ finishes at $27.2^{\circ} \mathrm{C}$.

The $\mathrm{A} \leftrightarrow \mathrm{R}$ transformation is used for US Ni-Ti® and Neo Sentalloy F100@ because the transformation temperatures to martensite are too low. In superelasticity, this wire shows an unloading plateau of 1600 g.mm which is too high a level for a central incisor.

Copper $\mathrm{Ni}-\mathrm{Ti}$, which is characterized by direct transformation from austenite to martensite, never experiences the R-phase (Table 2). DSC measurements of Copper Ni-Ti $35 \oplus$ during cooling show that the martensitic transformation (Ms) occurs at $17.5^{\circ} \mathrm{C}$ (Table 2). When the wire is loaded at $22^{\circ} \mathrm{C}$, it is in the austenitic phase. Thus, the loading and the unloading curves for superelasticity are the same. A load of 910 g.mm allows the martensitic phase to appear and thus the orthodontic wire develops superelastic behaviour. When the wire is cooled at $0^{\circ} \mathrm{C}$, the material is partially martensitic $\left(\mathrm{M}_{\mathrm{f}}:-8.5^{\circ} \mathrm{C}\right)$. Therefore, the loading slope is more gradual than the unloading slope. At buccal temperature $\left(37^{\circ} \mathrm{C}\right)$, the wire, after unloading, presents no permanent deformation because the reverse martensitic transformation is finished at $36.3^{\circ} \mathrm{C}$.

The transformation temperature of Copper $\mathrm{Ni}-\mathrm{Ti} 40 \oplus$ from austenite to martensite begins at $20.2^{\circ} \mathrm{C}$. Thus, a load of $560 \mathrm{~g} . \mathrm{mm}$ is enough to provoke the superelasticity. The restoring moments delivered by this wire are weaker than those delivered by Copper $\mathrm{Ni}-\mathrm{Ti} 35 \odot$. After cooling at $0^{\circ} \mathrm{C}$, the material is completely martensitic $\left(\mathrm{M}_{\mathrm{f}}: 3^{\circ} \mathrm{C}\right)$. Hence, the loading slope is more gradual than the unloading slope. At $37^{\circ} \mathrm{C}$, the wire remains partially martensitic because the transformation ends at $40^{\circ} \mathrm{C}$. Thus, after unloading, a permanent deformation remains : $<5^{\circ}$ torsion. But Copper $\mathrm{Ni}-\mathrm{Ti} 40\left(\right.$ wire could return to $0^{\circ}$ torsion only if the patient ate hot food. The restored moments of Copper Ni-Ti 408 are weaker than those observed in the case of the other wires.

\section{CONCLUSIONS}

Experimental study of $\mathrm{Ni}-\mathrm{Ti}$ and Copper $\mathrm{Ni}$-Ti alloy orthodontic wires in torsion give rise to the following observations. Compared to stainless steel archwires, these wires can produce slight forces and are able to endure great deformation in torsion without undergoing permanent deformation. The present results show that, in most cases, these wires have the ability to exhibit a plateau on unloading and thus produce a constant orthodontic force. Thus they provided the optimal conditions for tooth movement [10]. The level of the forces applied to the teeth depends on the transformation temperatures of $\mathrm{Ni}-\mathrm{Ti}$ and Copper $\mathrm{Ni}$ - $\mathrm{Ti}$ wires in relation to buccal temperature. The orthodontist can profitably use superelasticity or memory effect according to the clinical case. The clinician can choose between superelasticity and memory effect depending on the unloading level he is aiming at. During loading, the wire can easily be placed in the bracket without running the risk of bonding failure. $\mathrm{Ni}$ - $\mathrm{Ti}$ wires have other advantages like a reduction in the number of archwire changes needed to align teeth [11].

\section{References}

[1] Burstone C. J., Am. J. Orthod. 80 (1981) 1- 16.

[2] Miura F., Mogi M., Ohura Y. and Hamanaka H., Am. J. Orthod. Dentofac. Orthop. 90 (1986) $1-10$.

[3] Tonner R. I. M. and Waters N. E., Eur. J. Orthod. 16 (1994) 409-419.

[4] Guenin G., Techniques de l'Ingénieur 10 (1986) 1- 11.

[5] Miyazaki S. and Otsuka K., Metall. Trans. 17A (1986) 53-63.

[6] Jordan L., Chandrasekaran M., Masse M. and Bouquet G., J. Phys. IV 5 (1995) 489-494.

[7] Jordan L., Masse M., Collier J.Y.and Bouquet G., J. Phys. IV 4 (1994) 157-162.

[8] Filleul M.P., French patent N ${ }^{\circ} 89 / 06480$ (1989).

[9] Creekmore T. D., J. Clin. Orthod. 13 (1979) 305-310.

[10] Baron R., Rev. Orthop. Dento Fac. 9 (1975) 309-325.

[11] Bishara S., Winterbottom J., Sulieman A.H., Rim K. and Jakobsen J., Angle Orthod. 65 (1995) $117-122$. 